\title{
Hand-held cardiac ultrasound examinations performed in primary care patients by nonexperts to identify reduced ejection fraction
}

\author{
G. Nilsson ${ }^{1,2^{*}}$ (D, L. Söderström ${ }^{3}$, K. Alverlind ${ }^{3}$, E. Samuelsson ${ }^{1}$ and T. Mooe ${ }^{1}$
}

\begin{abstract}
Background: Early identification of patients with reduced left ventricular ejection fraction (LVEF) could facilitate the care of patients with suspected heart failure (HF). We examined if (1) focused cardiac ultrasound (FCU) performed with a hand-held device (Vscan 1.2) could identify patients with LVEF $<50 \%$, and (2) the distribution of HF types among patients with suspected HF seen at primary care clinics.

Methods: FCU performed by general practitioners (GPs)/GP registrars after a training programme comprising 20 supervised FCU examinations were compared with the corresponding results from conventional cardiac ultrasound by specialists. The agreement between groups of estimated LVEF $<50 \%$, after visual assessment of global left ventricular function, was compared. Types of HF were determined according to the outcomes from the reference examinations and serum levels of natriuretic peptides (NT-proBNP).

Results: One hundred patients were examined by FCU that was performed by $1-4$ independent examiners as well as by the reference method, contributing to 140 examinations (false positive rate, 19.0\%; false negative rate, 52.6\%; sensitivity, 47.4\% [95\% confidence interval [Cl]: 27.3-68.3]; specificity, 81.0\% [95\% Cl: 73.1-87.0]; Cohen's $\mathrm{k}$ measure for agreement $=0.22$ [95\% Cl: 0.03-0.40]). Among patients with false negative examinations, $1 / 7$ had HF with LVEF $<40 \%$, while the others had HF with LVEF $40-49 \%$ or did not meet the full criteria for HF. In patients with NT-proBNP $>125 \mathrm{ng} / \mathrm{L}$ and fulfilling the criteria for HF (68/94), HF with preserved LVEF ( $\geq 50 \%)$ predominated, followed by mid-range $(40-49 \%)$ or reduced LVEF $(<40 \%)$ HF types (53.2, 11.7 and $7.4 \%$, respectively).

Conclusions: There was poor agreement between expert examiners using standard ultrasound equipment and non-experts using a handheld ultrasound device to identify patients with reduced LVEF. Asides from possible shortcomings of the training programme, the poor performance of non-experts could be explained by their limited experience in identifying left ventricular dysfunction because of the low percentage of patients with HF and reduced ejection fraction seen in the primary care setting.
\end{abstract}

Trial registration: The study was registered at ClinicalTrials.gov (NCT02939157). Registered 19 October 2016. Keywords: Echocardiography, Heart failure, Primary care, Clinical trial

\footnotetext{
* Correspondence: gunnar.nilsson@regionjh.se

${ }^{1}$ Department of Public Health and Clinical Medicine, Umeå University, 90187 Umeå, Sweden

2Department of Public Health and Clinical Medicine, Unit of Research,

Education and Development-Östersund Hospital, Box 654, 83127 Östersund,

Sweden

Full list of author information is available at the end of the article
}

(c) The Author(s). 2019 Open Access This article is distributed under the terms of the Creative Commons Attribution 4.0 International License (http://creativecommons.org/licenses/by/4.0/), which permits unrestricted use, distribution, and reproduction in any medium, provided you give appropriate credit to the original author(s) and the source, provide a link to the Creative Commons license, and indicate if changes were made. The Creative Commons Public Domain Dedication waiver (http://creativecommons.org/publicdomain/zero/1.0/) applies to the data made available in this article, unless otherwise stated. 


\section{Background}

Patients attending primary care with symptoms indicating heart failure (HF) could benefit from faster diagnostic procedures that are conducted at the point of care. After clinical evaluation and electrocardiography, the next step in diagnosing HF is normally testing for natriuretic peptides and an echocardiography, which are performed at a hospital clinic. Because no single symptom of HF is specific, echocardiography is mandatory for establishing the diagnosis and to distinguish between the different types of HF. Additionally, it has important implications for the therapeutic possibilities [1-6]. The terminology of HF has been revised and three subtypes of HF are described based on levels of natriuretic peptides and left ventricular ejection fraction (LVEF); HF with reduced ejection fraction (HFrEF), $\mathrm{HF}$ with mid-range ejection fraction (HFmrEF), and HF with preserved ejection fraction (HFpEF) [6]. Since serum levels of natriuretic peptides overlap between the types of $\mathrm{HF}$, and elevated values are also seen in patients with other medical conditions (e.g., renal failure, atrial fibrillation, and advanced age), natriuretic peptide levels are mainly used to rule-out HF in patients with a level below the cut-point for exclusion (N-terminal pro-B-type natriuretic peptide [NTproBNP] $<125 \mathrm{pg} / \mathrm{ml}$ in the non-acute setting) [7-14]. In recent years, examinations performed by handheld ultrasound platforms were introduced as an extension of the traditional clinical examination of patients presenting with cardiac symptoms, an examination known as focused cardiac ultrasound (FCU). FCU performed with handheld devices has limitations demanding an evaluation in the clinical setting where the technique is intended for use [15-18]. These handheld ultrasound devices provide a twodimensional view of the heart, and some also have a colour-Doppler mode but with no continuous or pulsed Doppler modes, which limits the range of possibilities for diagnosing diastolic dysfunction [19-22]. The possibility of diagnosing left ventricular systolic impairment with good accuracy using hand-held ultrasound devices is reported in several studies that were conducted at cardiology wards and in other hospital settings [21-26]. Early identification of reduced LVEF in patients with symptoms indicative of HF could facilitate the care of patients that are evaluated by general practitioners (GPs). However, only a few studies of FCU have been reported so far from relevant primary care settings [27, 28]. Therefore, we examined whether FCU could be used to identify patients with reduced ejection fraction (LVEF < 50\%) among patients with suspected HF visiting primary care clinics. Furthermore, we examined the distribution of HF classes, in the population studied.

\section{Methods}

Design

FCU was conducted by non-expert physicians after a training programme comprising 20 supervised sessions.
Conventional cardiac ultrasound was performed by specialized staff as a reference.

\section{Setting and participants}

Men and women aged $\geq 20$ years residing in the Region Jämtland Härjedalen, northern Sweden (adult population 100,396 inhabitants at the end of 2016) were eligible. Primary-care patients who were referred for ultrasound examinations to diagnose or to guide treatment of $\mathrm{HF}$ were invited to the study. The FCU examinations were performed at the Clinical Research Centre and reference examinations were performed at the Department of Clinical Physiology, both at Östersund Hospital. Enrolment was carried out from December 12, 2016 to June 15, 2017. Patients referred for follow-up of cardiac valve disorders, without a question of HF, were excluded.

Five GP registrars and one GP with no prior experience in cardiac ultrasound participated as examiners using FCU. Each patient in the study could be examined during the same visit by 1-4 examiners independently from each other. This design was chosen to enable more study examinations compared to a 1:1 design. The study and reference examinations were scheduled on the same day, with study examinations performed before the reference examinations whenever possible. The examiners evaluated their findings independently immediately after the examination and recorded the results in the patient's examination protocol.

\section{Training programme}

Primarily, the participating examiners received a 2-h lecture about the principles of diagnostic ultrasound and demonstrations of FCU and comprehensive cardiac ultrasound at the medical ward, Levanger Hospital, Norway. Thereafter, all subsequent training was conducted at the Clinical Research Centre, Östersund Hospital. The examiners received a textbook, and they were instructed to study the background of cardiac ultrasound and the video loops that showed normal and impaired cardiac function, which were provided in the corresponding e-book [29]. The examiners were also instructed to study video tutorials of cardiac ultrasound, which could be accessed on the website of the University of South Carolina School of Medicine [30]. A qualified ultrasound technician supervised the training. All six of the examiners in the study performed the twenty FCU examinations stipulated on individual study patients under supervision. After that, later examinations were performed by the examiners independently. The supervised training sessions were scheduled every other week from December 12, 2016, with the last examiner completing the training period on April 18, 2017. The training focused on obtaining representative imaging views for assessment of cardiac function in defined standard-imaging views (parasternal long-axis and 
short-axis views, apical 4-chamber and subcostal views). LVEF was evaluated through visual assessment of global left ventricular function and graded as normal $(\geq 50 \%)$, reduced $(<50 \%)$, or severely reduced $(<30 \%)$. After examining the last study patient enrolled in the study, the recorded film sequences were evaluated for quality by a cardiologist experienced in cardiac ultrasound, without access to any other patient-related data. The examinations were anonymised with respect to the identity of the examiner and study patient and evaluated in random order as "acceptable" (1) or "not acceptable" (0) for diagnostic purposes. Inadequate projections and failure to record images were classified as "not acceptable" (0).

\section{Study and reference examinations}

The FCU examinations (study method) were performed with the imaging device, Vscan V1.2 (GE Vingmed Ultrasound, Horten, Norway, CE0470). The Vscan is equipped with a phased array transducer $(1.7-3.8 \mathrm{MHz})$, and has a screen dimension of $8.9 \mathrm{~cm}$, image resolution (pixels) of $240 \times 320$, and grey scale and colour Doppler. The Vscan platform allows for digital storage of still frames and loops of cardiac cycles predefined to $2 \mathrm{~s}$ without ECG signal, MMode, and continuous or pulsed Doppler modalities $[19,31]$. The recordings were stored on a micro-SD card and transferred using commercial software (Gateway; GE Vingmed Ultrasound) to a separate computer. The reference examinations were conducted on a Siemens Acuson S2000 platform including two-dimensional Doppler and tissue Doppler modalities for assessing systolic and diastolic functions. LVEF was assessed visually and graded as markedly reduced $(<30 \%)$, reduced $(<40 \%)$, mid-range (40-49\%), or preserved ( $\geq 50 \%)$. Diastolic function was evaluated according to Doppler estimates of velocities and deceleration times [32]. The reference examinations were conducted by qualified ultrasound technicians and evaluated by physicians specialized in clinical physiology or cardiology. Results of the reference and study examinations were not communicated to study patients during the examination sessions. A notice stating the results of the reference examination was sent back to the patient's GP. Observations from the FCU examinations were only used within the study.

The examinations were conducted in the left lateral position (parasternal and apical views) or in the supine position (subcostal view). The duration of the study examinations was about $15 \mathrm{~min}$, excluding time for protocol-related procedures.

When each study examination was completed, serum NT-proBNP levels were analysed on a Cobas $6000 \mathrm{M}$ module (Roche Diagnostics), with a range of measurement of 5-35,000 ng/L (Department of Clinical Chemistry, Östersund Hospital).

\section{Outcome measurements}

Agreement between the FCU and reference method was estimated, with a cut-off at LVEF $<50 \%$. Heart failure criteria and classification were based on the results from the reference examinations and NT-proBNP levels. HF in study patients was classified according to the 2016 ESC Guidelines [6]: "Heart failure with reduced ejection fraction (HFrEF): Patients with LVEF $<40 \%$. Heart failure with mid-range ejection fraction (HFmrEF): Patients with LVEF $40 \%$ to $49 \%$, NT-proBNP > $125 \mathrm{ng} / \mathrm{L}$, and at least one additional criterion: Signs of relevant structural heart disease (LVH and/or LAE), or diastolic dysfunction. Heart failure with preserved ejection fraction (HFpEF): Patients with LVEF $\geq 50 \%$, NT-proBNP > $125 \mathrm{ng} / \mathrm{L}$, and at least one additional criterion: Signs of relevant structural heart disease (LVH and/or LAE), or diastolic dysfunction, $(\mathrm{LVH}=$ left ventricular hypertrophy; $\mathrm{LAE}=$ left atrial enlargement; diastolic dysfunction $=$ assessment through conventional ultrasound examination incorporating relevant two-dimensional and Doppler data)".

Table 1 Characteristics of the study patient participants $(n=158)$

\begin{tabular}{lc}
\hline Age, mean (SD), years & $69.9(11.9)$ \\
Female sex & $71(44.9 \%)$ \\
NT-proBNP, ng/L, median (IQR) & $195(738)$ \\
Body mass index in kg/m², mean (SD) & $28.2(4.2)$ \\
Medical history, n/N (\%) & \\
Chronic Heart failure, medication for & $34 / 158(21.5 \%)$ \\
Hypertension, medication for & $97 / 158(61.4 \%)$ \\
Diabetes mellitus, treatment for & $28 / 158(17.7 \%)$ \\
Dyslipidaemia, medication for & $55 / 158(34.8 \%)$ \\
Asthma or COPD & $24 / 158(15.2 \%)$ \\
Revascularisation & $21 / 158(13.3 \%)$ \\
AMl & $16 / 157(10.2 \%)$ \\
Stroke or TIA & $18 / 158(11.4 \%)$ \\
Symptoms, n/N (\%) & \\
Orthopnea & $23 / 157(14.6 \%)$ \\
$\quad$ Nocturnal dyspnoea & $30 / 158(19.0 \%)$ \\
Ankle oedema & $50 / 158(31.6 \%)$ \\
Limitation of physical activity (NYHA I-IV), n/N (\%) & \\
No limitation of physical activity & $65 / 156(41.7 \%)$ \\
Slight limitation of physical activity & $59 / 156(37.8 \%)$ \\
Marked limitation of physical activity & $29 / 156(18.6 \%)$ \\
Siscomfort with any physical activity/ & $3 / 156(1.9 \%)$ \\
$\quad$ Exertional chest pain, n/N (\%) & $50 / 155(32.3 \%)$ \\
\hline
\end{tabular}

NT-proBNP N-terminal pro-B-type natriuretic peptide, COPD Chronic obstructive pulmonary disease, revascularisation = coronary bypass grafting or percutaneous coronary intervention; AMI Acute myocardial infarction, TIA Transitory ischaemic attack, NYHA New York Heart Association Functional Classification, SD Standard deviation, IQR Interquartile range 


\section{Study size}

The study was approved to include up to 250 study patients (including patients examined during the training period). The sample size was estimated from a pragmatic standpoint, based on the availability of study patients, time, and funding constraints and previously published experiences [28].

\section{Data analysis}

Demographic data are presented as proportions, means \pm standard deviations, or median and interquartile range for data not following a normal distribution. Betweengroup analysis of proportions was made via $X^{2}$ statistics or the Fisher exact test, as applicable. Agreement between the study and reference methods (LVEF < 50\%) were calculated via the Cohen's kappa coefficient $(\kappa)$, and sensitivity and specificity were determined from the proportion of patients with true-positive and true-negative results, with 95\% confidence intervals (CIs). Sensitivity and specificity calculations with $95 \%$ CIs were calculated with the software application WINPEPI, version 11.26 [33]. Other statistical analyses were performed with IBM SPSS (version 23).

\section{Results}

Of 282 eligible study patients, 158 were enrolled, of which 58 patients were only examined during the training period. Enrolment was stopped after 6 months due to the time constraints of the study plan. The mean age of study patients was 69.9 years. Limited physical ability (slight limitation 37.8\%, marked limitation 18.6\%), exertional chest pain (32.3\%), and cardiovascular and pulmonary comorbidities (hypertension 61.4\%, previous myocardial infarction $10.2 \%$ ) were common (Table 1).

One hundred individual patients were examined with both FCU and the reference method, contributing to 140 individual study examinations (Fig. 1). Of the study patients, 65 were examined by 1 examiner, 31 by 2 examiners, 3 by 3 examiners, and 1 patient by 4 examiners. Each examination was performed independently of the others. The number of independent examinations per examiner after the training period was $7-76$, (median 15)

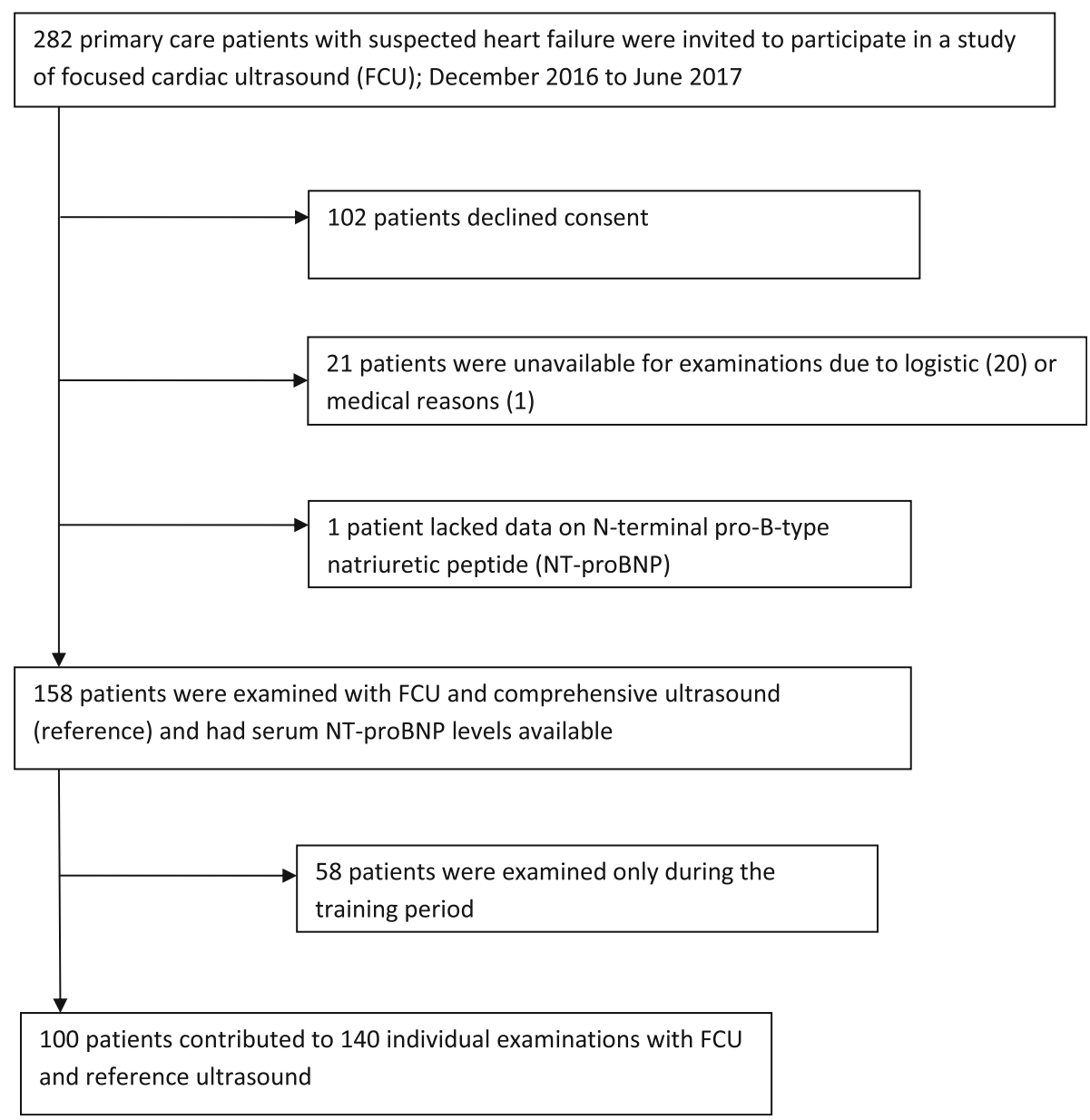

Fig. 1 Study profile of patient recruitment 
Table 2 Number of independently performed study examinations per examiner after training period

\begin{tabular}{ll}
\hline Examiner Number & Number of examinations after the training period \\
\hline 1 & 76 \\
2 & 20 \\
3 & 19 \\
4 & 10 \\
5 & 8 \\
6 & 7 \\
Total & 140 \\
\hline
\end{tabular}

(Table 2). One hundred and eleven patients were examined with FCU before and 47 after the reference examination, with an overall median time difference of $1.5 \mathrm{~h}$. During the training period, $80.0 \%$ of pictures obtained in the parasternal and apical views were evaluated as having acceptable image quality for diagnostic purposes, and the corresponding proportion in the independently obtained pictures was $80.6 \%$. The proportion of images that were of acceptable quality in the subcostal view was lower; overall, it was $39.8 \%$.

Agreement between the FCU and reference methods in identifying LVEF < $50 \%$ were as follows: false positive rate, 19.0\%; false negative rate, $52.6 \%$; sensitivity, $47.4 \%$ (95\% CI 27.3-68.3); specificity, $81.0 \%$ (95\% CI 73.1-87.0); and Cohen's k value, 0.22 (95\% CI 0.03-0.40) (Table 3). In patients with NT-proBNP-values > $125 \mathrm{ng} / \mathrm{L}$, the agreement between the study and reference methods remained low (Cohen's $\kappa=0.26$ [95\% CI $0.03-0.48]$ ), false positive rate $22.9 \%$, false negative rate $47.1 \%)$. Among the 7 individual study patients with a false negative examination (LVEF < $50 \%$ by reference examination but not by FCU), 1 patient fulfilled the criteria for HFrEF, 4 patients fulfilled criteria for HFmrEF, and 2 patients did not meet the defined criteria for $\mathrm{HF}$ according to the reference examination and NT-proBNP levels (10 examinations conducted in 7 patients). Among study patients with a false positive examination (LVEF < $50 \%$ by FCU but not by reference), 12/21

Table 3 Left ventricular ejection fraction (LVEF) determined by focused cardiac ultrasound (FCU) versus the reference examination $^{a}$

\begin{tabular}{lllll}
\hline & & \multicolumn{3}{l}{ Assessment of LVEF by FCU } \\
\cline { 3 - 5 } & & LVEF $<$ & LVEF $\geq$ & Total \\
& $50 \%$ & $50 \%$ & \\
\hline Comprehensive & LVEF $<$ & 9 & 10 & 19 \\
ultrasound (reference) & $50 \%$ & $(47.4 \%)$ & $(52.6 \%)$ & $(13.6 \%)$ \\
& LVEF $\geq$ & 23 & 98 & 121 \\
& $50 \%$ & $(19.0 \%)$ & $(81.0 \%)$ & $(86.4 \%)$ \\
& Total & 32 & 108 & 140 \\
& & $(22.9 \%)$ & $(77.1 \%)$ & \\
\hline
\end{tabular}

${ }^{\mathrm{a}} \mathrm{A}$ total of $140 \mathrm{FCU}$ examinations were performed in 100 patients fulfilled the criteria for HFpEF (23 examinations conducted in 21 study patients). Because few patients had LVEF < $30 \%$, these patients' data were not treated separately in the analyses.

The concordance between FCU and the reference method showed no trend toward an increase in the number of examinations per examiner ( $p$-value for trend $=0.298$ ) (Table 4). Among the six FCU examiners, the concordance between independently performed FCU examinations and the reference method ranged between 55.0 and $87.5 \%$ (mean $76.4 \%$ ).

The NT-proBNP levels (range 5 to $9923 \mathrm{ng} / \mathrm{L}$ ) overlapped between patients with and without $\mathrm{HF}$, but with a lower median value among patients without $\mathrm{HF}$ criteria (median $65 \mathrm{ng} / \mathrm{L}$; range 5 to 1292). All patients diagnosed with HFrEF had a NT-proBNP level that exceeded $700 \mathrm{ng} / \mathrm{L}$ (Table 5). In patients with a NT-proBNP value $>125 \mathrm{ng} / \mathrm{L}$, HF criteria (HFpEF, HFmrEF or HFrEF) were fulfilled in 68/94 (72.3\%); 50 for $\operatorname{HFpEF~(53.2\% ),~} 11$ for HFmrEF (11.7\%), and 7 for HFrEF (7.4\%). No patient with a BNP-level $\leq 125 \mathrm{ng} / \mathrm{L}(n=64)$ had HF (Table 6).

\section{Discussion}

This clinical trial showed that FCUs performed by GPs in the primary care setting failed to identify patients with impaired LVEF, when a comprehensive cardiac ultrasound was used as the reference. GPs attended a training programme comprising 20 supervised FCU sessions before the start of the study. However, the agreement between FCU and comprehensive cardiac ultrasound by experts (reference) was low (Cohen's $\mathrm{\kappa}$ value $=0.22$; sensitivity $47.4 \%$; specificity $81.0 \%$ ). Of patients with a false negative result, only one had HFrEF (LVEF< 40\%), while the other patients with false negative results had HFmrEF (LVEF 40-49\%) or did not fulfil the criteria for HF according to the 2016 ESC guidelines. In patients with NT-proBNP > $125 \mathrm{ng} / \mathrm{L}$, the levels of NT-proBNP did not differentiate between the types of HF (HFrEF, HFmrEF, HFpEF), with HFpEF as the predominant type,

Table 4 Agreement (LVEF < 50\%) between focused cardiac ultrasound (FCU) and comprehensive ultrasound (reference) ${ }^{a}$

\begin{tabular}{llll}
\hline $\begin{array}{llll}\text { Number of } \\
\text { examinations }\end{array}$ & \multicolumn{2}{l}{ Examination result } & $\begin{array}{l}\text { Total } \\
\text { number of } \\
\text { examinations }\end{array}$ \\
\cline { 2 - 3 } & Concordance & Discordance & \\
\hline $1-10$ & $19(76.0 \%)$ & $6(24.0 \%)$ & 25 \\
$11-20$ & $26(66.7 \%)$ & $13(33.3 \%)$ & 39 \\
$>20$ & $62(81.6 \%)$ & $14(18.4 \%)$ & 76 \\
Total & $107(76.4 \%)$ & $33(23.6 \%)$ & 140 \\
\hline
\end{tabular}

${ }^{a}$ The concordance or discordance by the number of FCU examinations independently performed per examiner in 100 study patients after an initial training period were compared with the reference method. Concordance was the agreement on the assessment of LVEF ( $<50 \%$ cut-off) by both methods LVEF Left ventricular ejection fraction 
Table 5 Heart failure types and their relationship with natriuretic peptide (NT-proBNP) levels in primary care patients ${ }^{a}$

\begin{tabular}{lll}
\hline Heart failure type & $\begin{array}{l}\text { NT-proBNP (ng/L), } \\
\text { median (min - max) }\end{array}$ & $\begin{array}{c}\text { Number of } \\
\text { patients (\%) }\end{array}$ \\
\hline Heart failure with preserved ejection fraction (HFpEF) & $757(131-9923)$ & $50(31.6 \%)$ \\
Heart failure with mid-range ejection fraction (HFmrEF) & $1311(239-2656)$ & $11(7.0 \%)$ \\
Heart failure with reduced ejection fraction (HFrEF) & $931(709-5595)$ & $7(4.4 \%)$ \\
Heart-failure criteria not fulfilled & $65(5-1292)$ & $90(57.0 \%)$ \\
\hline
\end{tabular}

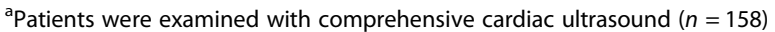

NT-proBNP N-terminal pro-B type natriuretic peptide, serum level in ng/L. HFpEF was defined as LVEF $\geq 50 \%, \mathrm{NT}$-proBNP $>125 \mathrm{ng} / \mathrm{L}$, and at least one additional criterion; a) signs of relevant structural heart disease (LVH and/or LAE) or b) diastolic dysfunction. HFmrEF was defined as LVEF 40 to $49 \%$, NT-proBNP > $125 \mathrm{ng} / \mathrm{L}$, and at least one additional criterion; a) or b). HFrEF was defined as LVEF $<40 \%$. LVH Left ventricular hypertrophy, LAE Left atrial enlargement

before HFmrEF and HFrEF. No HF was diagnosed in patients with NT-proBNP levels $\leq 125 \mathrm{ng} / \mathrm{L}$.

In this study, the poor agreement between FCU and comprehensive cardiac ultrasound conflicts with previous reports of FCU conducted by both expert [21, 23, 31] and non-expert examiners that found a good overall agreement in patients recruited from hospital-based medical wards [24, 25, 34-36], with a diagnostic accuracy greater than $90 \%$ in some reports. The reasons for the disagreement between findings might include the following:

1. The supervised FCU training sessions were mainly focused on acquiring representative imaging views and less focused on interpretation of findings.

2. The use of web-based tutorials provided no opportunity for feedback on the cardiac function assessments during individual examinations. Mjölstad and colleagues reported a sensitivity of $92 \%$ and specificity of $94 \%$ using a hand-held ultrasound device (Vscan 1.2) and eye-balling of the LVEF as " $>45,30-45$, or $<30 \%$, corresponding to normal/near normal, moderate, or severe dysfunction, respectively". In this study, the participating residents had a personal supervisor with whom they could discuss their findings during a tutorial period comprising at least 100 examinations [24].

3. The number of supervised training sessions and the period for learning on the FCU might have been insufficient to learn the technical aspects of FCU and to gain confidence in interpreting the images. Nonetheless, the amount of training in the prior positive reports of FCU learning programmes for non-experts was highly diverse, ranging from $2 \mathrm{~h}$ to 3 months [24, 25, 34-39] or 10 to 100 examinations $[26,40-42]$.

4. Differences in the types of outcome measurements; in previous reports on training programmes for handheld ultrasound devices designed for GP graduates or GP registrars (training periods ranging from $8 \mathrm{~h}$ to 4 weeks), success was assessed by proxy measurements. These measurements included septal mitral annular excursion (sMAE), a surrogate measure of left ventricular systolic function, improvement on examiner's test-scores, or self-perceived proficiency [28, 43, 44]. Even when accounting for differences in outcome measurements, there is no consensus concerning the ideal training programme for use of FCU by non-experts. The design of our training programme, with 20 supervised examinations, focused on technique and web-based learning about the interpretation of images, and was based on a pragmatic point of view after a search of the relevant literature.

5. The demography and types of HF differ between patients seen in cardiology wards and in primary care clinics, with more patients with HFpEF, or "diastolic heart failure", seen in the primary care setting [45]. This has consequences due to the technical limitations of the handheld ultrasound

Table 6 Diagnostic outcomes by NT-proBNP (125 ng/L cut-off)

\begin{tabular}{|c|c|c|c|}
\hline Diagnostic outcome & $\begin{array}{l}\text { NT-proBNP }>125 \mathrm{ng} / \mathrm{L} \\
(n=94), \mathrm{n}(\%)\end{array}$ & $\begin{array}{l}\text { NT-proBNP } \leq 125 \mathrm{ng} / \mathrm{L} \\
(n=64), \mathrm{n}(\%)\end{array}$ & $\begin{array}{l}P \text { value for } \\
\text { difference }\end{array}$ \\
\hline HFpEF & $50(53.2 \%)$ & NA & NA \\
\hline HFmrEF & $11(11.7 \%)$ & NA & NA \\
\hline HFrEF & $7(7.4 \%)$ & 0 & 0.042 \\
\hline Heart-failure criteria not fulfilled & $26(27.7 \%)$ & $64(100 \%)$ & $<0.001$ \\
\hline
\end{tabular}


devices (Vscan and other models), since evaluation of diastolic dysfunction demands Doppler modes that are not provided in the handheld platforms $[19,20]$. In study patients with a false negative examination (LVEF $<50 \%$ by reference but not by FCU), one of seven patients was type HFrEF according to the reference examination, while the other patients were type HFmrEF or did not fulfil the complete criteria for HF. Thus, the poor performance in acquiring and assessing FCUs shown by the participants in our study could be linked to the low prevalence of patients with HFrEF, relative to the numbers of patients with the other types of HF commonly observed in the primary care setting. Since the symptoms of HF are nonspecific and not discriminatory between the types of HF, the issue of diagnosing all types of HF correctly is still essential due to differences in prognoses and therapeutic options; e.g., reductions in morbidity and mortality from pharmacotherapy are only shown in patients with LVEF reduced $<40 \%[6,46,47]$.

The serum NT-proBNP levels between types of HF, and between patients with and without HF, overlapped, although the median value was higher in patients who fulfilled the HF criteria. In patients with NT-proBNP $>125 \mathrm{ng} / \mathrm{L}$, the poor agreement in LVEF between FCU and comprehensive cardiac ultrasound remained, indicating that pre-selection of patients by NT-proBNP levels $>125 \mathrm{ng} / \mathrm{L}$ will not necessarily lead to more accurate diagnostic results, although patients with NT-proBNP levels $\leq 125 \mathrm{ng} / \mathrm{L}$ are highly unlikely to have HF. The predominance of HFpEF before patients with HF with mid-range or reduced EF and the high prevalence of hypertension was in line with previous reports from population-based cohorts [45, 48, 49].

The overall percentage of ultrasound images that were of acceptable quality (about 80\%) obtained in the main imaging views (parasternal long- and short-axis and apical four chamber) was comparable to those in previous studies (73.8-89\%) [27, 34, 37]. In our study, we found that the subcostal imaging view was the most difficult to obtain correctly, similar to findings reported by Kobal et al. [37]. We would have preferred to provide prolonged training, with feedback for each trainee on their own FCU examinations; however, limited access to appropriately trained supervisors is a barrier to expanding such training programmes in the primary care setting [50]. Adequate image quality does not necessarily correspond to a correct assessment of cardiac function. Thus, sending the FCUs to a remote expert for interpretation might be a solution, particularly in remote areas $[27,51]$. Since the agreement between the FCU and comprehensive cardiac ultrasound results was low, our training programme should be modified; e.g., with more opportunities to receive feedback on interpretation of the images. The ideal FCU training programme remains to be determined.

Our study has limitations. Only six individual examiners were evaluated in the training programme. The demographics of the non-consenting patients, about one third of all those eligible, are unknown, but could have influenced the results. The reference examinations were conducted by different expert examiners following a protocol for cardiac ultrasound examination in patients under normal care.

In further research on FCU in a primary care setting, remote expert interpretative support and methods to overcome the difficulties in assessing patients with HF who have mid-range and preserved EF should be addressed.

\section{Conclusions}

There was poor agreement between findings from conventional ultrasound equipment and those from a handheld device used by non-experts in identifying reduced LVEF. Besides the limitations in the number of supervised training sessions and feedback opportunities, the poor performance of FCU in our study could be explained by the criterion chosen for reduced LVEF and a lower prevalence of patients with reduced LVEF in the primary care setting.

\section{Abbreviations \\ Cl: Confidence interval; FCU: Focused cardiac ultrasound; GP: General practitioner; HF: Heart failure; HFmrEF: Heart failure with mid-range ejection fraction; HFpEF: Heart failure with preserved ejection fraction; HFrEF: Heart failure with reduced ejection fraction; LAE: Left atrial enlargement; LVEF: Left ventricular ejection fraction; LVH: Left ventricular hypertrophy; NT-proBNP: N- terminal pro-B-type natriuretic peptide; sMAE: Septal mitral annular excursion; k: Cohen's kappa coefficient}

\section{Acknowledgements}

We would like to thank Karin Forsberg, ultrasound technician and supervisor of the FCU training programme, and Håvard Dalen and the staff at the medical ward, Levanger Hospital, Norway.

\section{Authors' contributions}

GN, LS, ES, and TM conceived the study. LS supervised the statistical analyses. TM and KA took part in the assessment and quality analysis of the ultrasound images. All authors drafted the manuscript and approved of the final version of the manuscript.

\section{Funding}

The study was funded by grants from Vinnova (Sweden's innovation agency) 2016-02514) and from the Region Jämtland Härjedalen. The funders had no role in the design of the study or collection, analysis and interpretation of data, or in writing the manuscript.

\section{Availability of data and materials}

The datasets obtained during the study will be available from the corresponding author on reasonable request. 


\section{Ethics approval and consent to participate}

Before enrolment of study patients, ethical approval was obtained from the Regional Ethical Review Board at Umeå University (2016/337-31) and the study was registered at ClinicalTrials.gov (NCT02939157). All participants provided written informed consent before enrolment.

\section{Consent for publication}

Not applicable.

\section{Competing interests}

The authors declare that they have no competing interests.

\section{Author details}

'Department of Public Health and Clinical Medicine, Umeå University, 90187 Umeå, Sweden. ${ }^{2}$ Department of Public Health and Clinical Medicine, Unit of Research, Education and Development-Östersund Hospital, Box 654, 83127 Östersund, Sweden. ${ }^{3}$ Unit of Research, Education and Development-Östersund Hospital, Region Jämtland Härjedalen, Östersund, Sweden

Received: 7 February 2019 Accepted: 16 July 2019

Published online: 25 July 2019

\section{References}

1. Fonseca C. Diagnosis of heart failure in primary care. Heart Fail Rev. 2006;11: 95-107.

2. Gimelli A, Lancellotti P, Badano LP, Lombardi M, Gerber B, Plein S, et al. Non-invasive cardiac imaging evaluation of patients with chronic systolic heart failure: a report from the European Association of Cardiovascular Imaging (EACVI). Eur Heart J. 2014;35:3417-25.

3. Kelder JC, Cramer MJ, van Wijngaarden J, van Tooren R, Mosterd A, Moons $\mathrm{KG}$, et al. The diagnostic value of physical examination and additional testing in primary care patients with suspected heart failure. Circulation. 2011;124:2865-73.

4. Lang RM, Badano LP, Mor-Avi V, Afilalo J, Armstrong A, Ernande L, et al. Recommendations for cardiac chamber quantification by echocardiography in adults: an update from the American Society of Echocardiography and the European Association of Cardiovascular Imaging. Eur Heart J Cardiovasc Imaging. 2015;16:233-70.

5. Oudejans I, Mosterd A, Bloemen JA, Valk MJ, van Velzen E, Wielders JP, et al. Clinical evaluation of geriatric outpatients with suspected heart failure: value of symptoms, signs, and additional tests. Eur J Heart Fail. 2011;13:518-27.

6. Ponikowski P, Voors AA, Anker SD, Bueno H, Cleland JGF, Coats AJS, et al. 2016 ESC guidelines for the diagnosis and treatment of acute and chronic heart failure: the task force for the diagnosis and treatment of acute and chronic heart failure of the European Society of Cardiology (ESC) developed with the special contribution of the heart failure association (HFA) of the ESC. Eur Heart J. 2016:37:2129-200.

7. Cowie MR, Struthers AD, Wood DA, Coats AJ, Thompson SG, Poole-Wilson $P A$, et al. Value of natriuretic peptides in assessment of patients with possible new heart failure in primary care. Lancet. 1997;350:1349-53.

8. Fuat A, Murphy JJ, Hungin AP, Curry J, Mehrzad AA, Hetherington A, et al. The diagnostic accuracy and utility of a B-type natriuretic peptide test in a community population of patients with suspected heart failure. Brit J Gen Pract. 2006;56:327-33.

9. Kelder JC, Cramer MJ, Verweij WM, Grobbee DE, Hoes AW. Clinical utility of three B-type natriuretic peptide assays for the initial diagnostic assessment of new slow-onset heart failure. J Card Fail. 2011;17:729-34.

10. Krishnaswamy P, Lubien E, Clopton P, Koon J, Kazanegra R, Wanner E, et al. Utility of B-natriuretic peptide levels in identifying patients with left ventricular systolic or diastolic dysfunction. Am J Med. 2001;111:274-9.

11. Maisel A, Mueller C, Adams K Jr, Anker SD, Aspromonte N, Cleland JG, et al. State of the art: using natriuretic peptide levels in clinical practice. Eur J Heart Fail. 2008;10:824-39.

12. Roberts E, Ludman AJ, Dworzynski K, Al-Mohammad A, Cowie MR, McMurray JJ, et al. The diagnostic accuracy of the natriuretic peptides in heart failure: systematic review and diagnostic meta-analysis in the acute care setting. BMJ. 2015;350:h910.

13. Yamamoto K, Burnett JC Jr, Bermudez EA, Jougasaki M, Bailey KR, Redfield MM. Clinical criteria and biochemical markers for the detection of systolic dysfunction. J Card Fail. 2000;6:194-200.
14. Zaphiriou A, Robb S, Murray-Thomas T, Mendez G, Fox K, McDonagh T, et al. The diagnostic accuracy of plasma BNP and NTproBNP in patients referred from primary care with suspected heart failure: results of the UK natriuretic peptide study. Eur J Heart Fail. 2005;7:537-41.

15. Kimura BJ, Gilcrease GW 3rd, Showalter BK, Phan JN, Wolfson T. Diagnostic performance of a pocket-sized ultrasound device for quick-look cardiac imaging. Am J Emerg Med. 2012;30:32-6.

16. Kobal SL, Atar S, Siegel RJ. Hand-carried ultrasound improves the bedside cardiovascular examination. Chest. 2004;126:693-701.

17. Liebo MJ, Israel RL, Lillie EO, Smith MR, Rubenson DS, Topol EJ. Is pocket mobile echocardiography the next-generation stethoscope? A crosssectional comparison of rapidly acquired images with standard transthoracic echocardiography. Ann Intern Medicine. 2011;155:33-8.

18. Mehta M, Jacobson T, Peters D, Le E, Chadderdon S, Allen AJ, et al. Handheld ultrasound versus physical examination in patients referred for transthoracic echocardiography for a suspected cardiac condition. JACC Cardiovasc Imaging. 2014;7:983-90.

19. Mirabel M, Celermajer D, Beraud AS, Jouven X, Marijon E, Hagege AA. Pocket-sized focused cardiac ultrasound: strengths and limitations. Arch Cardiovasc Dis. 2015;108:197-205.

20. Penicka M, Vanderheyden M, Bartunek J. Diagnosis of heart failure with preserved ejection fraction: role of clinical Doppler echocardiography. Heart. 2014;100:68-76.

21. Prinz C, Voigt JU. Diagnostic accuracy of a hand-held ultrasound scanner in routine patients referred for echocardiography. J Am Soc Echocardiogr. 2011;24:111-6.

22. Testuz A, Muller $H$, Keller PF, Meyer P, Stampfli $T$, Sekoranja $L$, et al. Diagnostic accuracy of pocket-size handheld echocardiographs used by cardiologists in the acute care setting. Eur Heart J Cardiovasc Imaging. 2013:14:38-42.

23. Andersen GN, Haugen BO, Graven T, Salvesen O, Mjolstad OC, Dalen H. Feasibility and reliability of point-of-care pocket-sized echocardiography. Eur J Echocardiogr. 2011;12:665-70.

24. Mjolstad OC, Andersen GN, Dalen H, Graven T, Skjetne K, Kleinau JO, et al. Feasibility and reliability of point-of-care pocket-size echocardiography performed by medical residents. Eur Heart $\rfloor$ Cardiovasc Imaging. 2013;14:1195-202.

25. Prinz C, Dohrmann J, van Buuren F, Bitter T, Bogunovic N, Horstkotte D, et al. The importance of training in echocardiography: a validation study using pocket echocardiography. J Cardiovasc Med (Hagerstown). 2012;13:700-7.

26. Razi R, Estrada JR, Doll J, Spencer KT. Bedside hand-carried ultrasound by internal medicine residents versus traditional clinical assessment for the identification of systolic dysfunction in patients admitted with decompensated heart failure. J Am Soc Echocardiogr. 2011;24:1319-24.

27. Evangelista A, Galuppo V, Mendez J, Evangelista L, Arpal L, Rubio C, et al. Hand-held cardiac ultrasound screening performed by family doctors with remote expert support interpretation. Heart. 2016;102:376-82.

28. Mjolstad OC, Snare SR, Folkvord L, Helland F, Grimsmo A, Torp H, et al. Assessment of left ventricular function by GPs using pocket-sized ultrasound. Fam Pract. 2012;29:534-40.

29. Soni NJ, Arntfield R, Kory P. Point of care ultrasound. 1st ed: Elsevier Saunders; 2015.

30. School of Medicine University of South Carolina. https://sc.edu/study/ colleges_schools/medicine/centers_and_institutes_new/ultrasound_ institute/resources.php. Acessed 14 Dec 2018.

31. Lafitte S, Alimazighi N, Reant P, Dijos M, Zaroui A, Mignot A, et al. Validation of the smallest pocket echoscopic device's diagnostic capabilities in heart investigation. Ultrasound Med Biol. 2011;37:798-804.

32. Nagueh SF, Smiseth OA, Appleton CP, Byrd BF 3rd, Dokainish H, Edvardsen $T$, et al. Recommendations for the evaluation of left ventricular diastolic function by echocardiography: an update from the American Society of Echocardiography and the European Association of Cardiovascular Imaging. J Am Soc Echocardiogr. 2016;29:277-314.

33. Abramson JH. WINPEPI updated: computer programs for epidemiologists, and their teaching potential. Epidemiol Perspect Innov. 2011;8:1.

34. Andersen GN, Viset A, Mjolstad OC, Salvesen O, Dalen H, Haugen BO. Feasibility and accuracy of point-of-care pocket-size ultrasonography performed by medical students. BMC Med Educ. 2014;14:156.

35. Lucas BP, Candotti C, Margeta B, Evans AT, Mba B, Baru J, et al. Diagnostic accuracy of hospitalist-performed hand-carried ultrasound echocardiography after a brief training program. J Hosp Med. 2009;4:340-9. 
36. Ruddox V, Norum IB, Stokke TM, Edvardsen T, Otterstad JE. Focused cardiac ultrasound by unselected residents-the challenges. BMC Med Imaging. 2017;17:22.

37. Kobal SL, Lior Y, Ben-Sasson A, Liel-Cohen N, Galante O, Fuchs L. The feasibility and efficacy of implementing a focused cardiac ultrasound course into a medical school curriculum. BMC Med Educ. 2017;17:94.

38. Ruddox V, Stokke TM, Edvardsen T, Hjelmesaeth J, Aune E, Baekkevar M, et al. The diagnostic accuracy of pocket-size cardiac ultrasound performed by unselected residents with minimal training. Int J Cardiovasc Imaging. 2013;29:1749-57.

39. Kobal SL, Trento L, Baharami S, Tolstrup K, Naqvi TZ, Cercek B, et al. Comparison of effectiveness of hand-carried ultrasound to bedside cardiovascular physical examination. Am J Cardiol. 2005;96:1002-6.

40. Decara JM, Kirkpatrick JN, Spencer KT, Ward RP, Kasza K, Furlong K, et al. Use of hand-carried ultrasound devices to augment the accuracy of medical student bedside cardiac diagnoses. J Am Soc Echocardiogr. 2005;18:257-63.

41. Hellmann DB, Whiting-O'Keefe Q, Shapiro EP, Martin LD, Martire C, Ziegelstein RC. The rate at which residents learn to use hand-held echocardiography at the bedside. Am J Med. 2005;118:1010-8.

42. Panoulas VF, Daigeler AL, Malaweera AS, Lota AS, Baskaran D, Rahman S, et al. Pocket-size hand-held cardiac ultrasound as an adjunct to clinical examination in the hands of medical students and junior doctors. Eur Heart J Cardiovasc Imaging. 2013;14:323-30.

43. Bornemann P. Assessment of a novel point-of-care ultrasound Curriculum's effect on competency measures in family medicine graduate medical education. J Ultrasound Med. 2017:36:1205-11.

44. Wong F, Franco Z, Phelan MB, Lam C, David A. Development of a pilot family medicine hand-carried ultrasound course. WMJ. 2013;112:257-61.

45. Mosterd A, Hoes AW. Clinical epidemiology of heart failure. Heart. 2007;93: $1137-46$.

46. Meta-analysis Global Group in Chronic Heart Failure (MAGGIC). The survival of patients with heart failure with preserved or reduced left ventricular ejection fraction: an individual patient data meta-analysis. Eur Heart J. 2012; 33:1750-7.

47. Lam CS, Solomon SD. The middle child in heart failure: heart failure with mid-range ejection fraction (40-50\%). Eur J Heart Fail. 2014;16:1049-55.

48. van Riet EE, Hoes AW, Limburg A, Landman MA, van der Hoeven H, Rutten $\mathrm{FH}$. Prevalence of unrecognized heart failure in older persons with shortness of breath on exertion. Eur J Heart Fail. 2014;16:772-7.

49. van Riet EE, Hoes AW, Wagenaar KP, Limburg A, Landman MA, Rutten FH. Epidemiology of heart failure: the prevalence of heart failure and ventricular dysfunction in older adults over time. A systematic review. Eur J Heart Fail. 2016;18:242-52.

50. Hall JW, Holman H, Bornemann P, Barreto T, Henderson D, Bennett K, et al. Point of care ultrasound in family medicine residency programs: a CERA study. Fam Med. 2015;47:706-11.

51. Choi BG, Mukherjee M, Dala P, Young HA, Tracy CM, Katz RJ, et al. Interpretation of remotely downloaded pocket-size cardiac ultrasound images on a web-enabled smartphone: validation against workstation evaluation. J Am Soc Echocardiogr. 2011;24:1325-30.

\section{Publisher's Note}

Springer Nature remains neutral with regard to jurisdictional claims in published maps and institutional affiliations.

Ready to submit your research? Choose BMC and benefit from:
- fast, convenient online submission
- thorough peer review by experienced researchers in your field
- rapid publication on acceptance
- support for research data, including large and complex data types
- gold Open Access which fosters wider collaboration and increased citations
- maximum visibility for your research: over 100M website views per year
At BMC, research is always in progress.
Learn more biomedcentral.com/submissions

